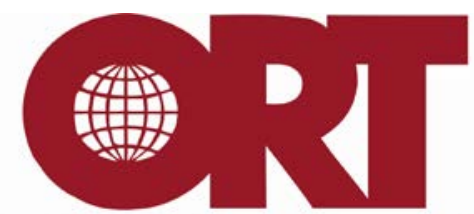

UNIVERSIDADORT

Uruguay

\title{
What do happiness and health satisfaction data tell us about relative risk aversion?*
}

\author{
Gandelman, Néstor \\ Universidad ORT Uruguay \\ Hernández-Murillo, Rubén \\ Federal Reserve Bank of St. Louis \\ Marzo de 2012
}

\begin{abstract}
In this paper we provide estimates of the coefficient of relative risk aversion using information on selfreports of subjective personal well-being from three datasets: the Gallup World Poll, the European Social Survey, and the World Values Survey. We additionally consider the implications of allowing for health state dependence in the utility function on estimates of risk aversion and examine how the marginal utility of income changes in poor health states. Our estimates of relative risk aversion vary closely around 1 (range 0.79 to 1.44 ), which corresponds to logarithmic utility. We find that controlling for health dependence generally reduces these estimates. In contrast to other studies in the literature, our results also suggest that the marginal utility of income increases when health deteriorates, and this effect is robust across the various datasets analyzed
\end{abstract}

JEL codes: D80, G00, I10, I31.

Keywords: relative risk aversion; marginal utility of income; happiness; health dependence.

Documento de Investigación, Nro. 74, marzo 2012. Universidad ORT Uruguay.

Facultad de Administración y Ciencias Sociales. ISSN 1688-6275

\footnotetext{
* The views expressed herein are those of the authors and do not reflect the official positions of the Federal Reserve Bank of St. Louis, the Federal Reserve Board of Governors, or the Federal Reserve System. Christopher J. Martinek provided research assistance. The authors thank the Inter-American Development Bank and the Gallup Organization for facilitating access to the Gallup World Poll.
} 


\section{Introduction}

Attitudes toward risk are a central issue in almost every economic problem involving decision making. Surprisingly, there is not yet a commonly accepted estimate of the coefficient of relative risk aversion. Many economists think that the coefficient of relative risk aversion probably lies between 1 and 3, but estimates vary widely in the literature, from as low as 0.2 to 10 or higher, particularly in the literature that uses inferences from behavioral choices to elicit risk aversion.

Among the studies based on behavioral choices, Friend and Blume (1975), studying the demand for risky assets, estimate that the coefficient of relative risk aversion generally exceeds 1 . Weber (1975), using expenditure data, and Szpiro, (1986), using data on property insurance, estimate relative risk aversion in the range between 1.3 and 1.8. Using consumption data, Hansen and Singleton (1983) report lower estimates: between 0.68 and 0.97. Also using data on consumption, Mankiw (1985) finds much larger estimates in the range of 2.44 to $5.26{ }^{1}$

In this paper, we use data on subjective self-reports of personal well-being to estimate the coefficient of relative risk aversion. The literature on the application of happiness or subjective well-being data to address economic issues originated with Easterlin's (1974) seminal paper, and since the late 1990s the amount of research that uses happiness and satisfaction databases has increased considerably; Frey and Stutzer (2002) and Di Tella and MacCulloch (2006) are two examples of reviews of the use of such data in economics.

In our analysis, we build on Layard, Mayraz, and Nickell (2008). They use happiness data to estimate how fast the marginal utility of income declines as income increases, an elasticity that corresponds to the parameter of relative risk aversion under a constant relative risk aversion utility function. These authors stress the importance of this interpretation of the parameter of interest for analyzing normative public economic issues, such as optimal taxation. Our paper extends their analysis by considering health state dependence in the utility function, as in Finkelstein, Luttmer, and Notowidigdo

\footnotetext{
${ }^{1}$ More recent studies continue to show a great disparity of estimates. Using a consumption-based capital asset pricing model with state-dependent risk aversion, Gordon and St-Amour (2004) find estimates in the range of 0 to 10. García. Luger and Renault (2003) using a generalization of a Black-Scholes option pricing model to S\&P 500 call option prices report estimates of relative risk aversion in the range of 0.83 to 3.28. Chetty (2006), studying the links among labor supply, risk aversion, and the curvature of the utility over consumption, finds a mean estimate of relative risk aversion of 0.71 with a range of 0.15 to 1.78. Campo et al. (2011) estimate a first-price auction model semiparametrically and report an estimate of relative risk aversion of 0.61 .
} 
(2008), and we stress the interpretation of the parameter of interest as a measure of risk aversion for analyzing financial problems such as determining the optimal amount of health insurance.

We use data from the Gallup World Poll (GWP), the European Social Survey (ESS), and the World Values Survey (WVS). The Gallup dataset only recently became available for applied research and covers a larger set of people than most subjective well-being surveys: about 70,000 individuals in more than 140 countries; we use data covering 103 countries. The largest dataset used by Layard, Mayraz, and Nickell (2008), for example, has only about 50 countries. We also use data from the ESS covering 27 countries and from the WVS covering 41 countries. From these surveys, in addition to demographic information on personal income, age, gender, marital status, and employment, we use information on self-reports of subjective well-being and satisfaction with personal health, which we use to study the implications of health status on relative risk aversion or the marginal utility of income.

We provide estimates of the coefficient of relative risk aversion for five groups of countries categorized by the World Bank in terms of income per capita. For each of the surveys we also provide overall estimates that use observations from all countries. In general, the estimates using the GWP data are slightly lower than 1, whereas the estimates with the ESS and the WVS were slightly larger than 1. Using the Gallup data, for example, we obtain an overall estimate or relative risk aversion of 0.79 ; the estimate is significantly different from 1.0, which corresponds to log utility. The overall estimates with the ESS and the WVS are slightly higher at 1.44 and 1.16, respectively, and are also significant and different from 1. Using the Gallup data, the pooled estimates for the various income country classes were mostly smaller than 1, suggesting a lower degree of concavity than logarithmic utility. On the other hand, the estimates by income classes with the ESS and the WVS data were slightly larger than 1, suggesting more concavity than logarithm utility. The estimate for the United States using the Gallup data is 1.48, which is similar to the estimates of by Layard, Mayraz, and Nickell (2008); the estimate for the United States using the WVS data is 0.9. However, using either the GWP or the WVS, we cannot reject the null of a relative risk aversion of 1 for the United Sates.

We also analyze the effect of controlling for health state dependence on the estimates of relative risk aversion. We find that the estimated relative risk aversion coefficients for country groups generally decline when we control for the dependence of 
the utility function on health status. We also find, in contrast to Finkelstein, Luttmer, and Notowidigdo (2008) that the marginal utility of income increases when health deteriorates. This result holds across the three different datasets we analyzed.

In the next section we describe the datasets used in the analysis. In Section 3 we present the methodology. We discuss the results in Section 4 and we provide concluding comments in Section 5.

\section{Data}

We use data from the 2006 GWP, the 2002-2006 ESS and the 1981-2008 WVS. The main variables of interest are self-reported happiness or satisfaction with life, assessment of personal health, and data on household income. We also use additional information on age, gender, marital status, employment status, and residence in urban areas.

\subsection{The Gallup World Poll}

The GWP is probably the world's most comprehensive database of behavioral economic measures. It surveys individuals in more than 140 countries representing about 95 percent of the world's adult population. In our study we use data on about 55,000 individuals from 103 countries.

While the GWP does not have a specific question on personal happiness (e.g., "How happy are you?"), it has a question on satisfaction with life that corresponds to a personal assessment of general well-being. The question in the survey reads "Please imagine a ladder/mountain with steps numbered from zero at the bottom to ten at the top. Suppose we say that the top of the ladder/mountain represents the best possible life for you and the bottom of the ladder/mountain represents the worst possible life for you. If the top step is 10 and the bottom step is 0 , on which step of the ladder/mountain do you feel you personally stand at the present time?" We use the ordered responses to this question as our measure of reported well-being, and henceforth we do not distinguish it from happiness.

As an indicator of health status we use the question on satisfaction with personal health "Are you satisfied or dissatisfied with your personal health?" with "yes" or "no" as possible answers. 
Household income data are reported in 29 brackets. We use the midpoint of the bracket as the measure of income, and for the top bracket we use a value equal to double the previous midpoint value. Although the data are supposed to represent monthly gross income, some countries report annual income. Furthermore, income data are reported in local currency for most countries (Gasparini et al. 2008). Therefore, for individuals in each country, we express the income measure in deviations from the country's average. ${ }^{2}$ We also eliminate outlier observations from the analysis (see Section 3).

\subsection{European Social Survey}

The first three rounds of the ESS conducted from 2002 to 2006 contain data on 27 countries. In our study we use data on 32,951 individuals.

The ESS asks respondents separate questions about their happiness and satisfaction with life. We use the happiness question that reads "Taking all things together, how happy would you say you are?" Respondents are asked to select a number from 0 (corresponding to extremely unhappy) to 10 (corresponding to extremely happy). We use the ordered responses to this question as our measure of reported well-being.

The health status indicator is derived from the ESS question that reads "How is your health in general? Would you say it is... ?" Respondents are asked to select one of five responses: very good, good, fair, bad, very bad. We create an indicator that distinguishes fair, bad and very bad responses from good and very good responses.

Household total net income data are reported in 12 brackets. The survey provides bracket intervals in Euro and when necessary, inserts corresponding national currencies. We use the midpoint of the bracket as the measure of income. For the bottom and top brackets we use a value equal to two-thirds of the bottom-code value and one and a half times the top-code value, respectively. Similar to the procedure used with the Gallup data, the income measure is expressed in deviations from the country's average and outlier observations are excluded from the analysis.

\footnotetext{
${ }^{2}$ This normalization also addresses the issue of making the measures comparable across countries, as there is no clear indication of which countries report income in local currency.
} 


\subsection{World Values Survey}

The WVS aggregated files contain data across 5 waves from 1981 to 2008 for 87 countries. In our study we use data on 38,500 individuals from 41 countries. $^{3}$

The WVS asks respondents separate questions about their happiness and satisfaction with life. The responses to the satisfaction with life question are provided on an ordinal scale comparable to the measures of well-being used in the other surveys so we use this as our measure of reported well-being. The life satisfaction question reads "All things considered, how satisfied are you with your life as a whole these days?" Respondents are asked to select a number from 1 (corresponding to dissatisfied) to 10 (corresponding to satisfied).

The health status indicator is derived from the WVS question that reads "All in all, how would you describe your state of health these days? Would you say it is...?" Respondents are asked to select one of five responses: very good, good, fair, bad, very bad. We create an indicator that distinguishes fair, bad, and very bad responses from good and very good responses.

Household gross income data are reported in 10 brackets. Specific bracket intervals in national currencies are not provided for all country-wave combinations. Data are excluded from the analysis when the country-specific bracket values are not known. We use the midpoint of the bracket as the measure of income. For the bottom and top brackets we use a value equal to two-thirds of the bottom-code value and one and a half times the top-code value, respectively. Similar to the procedure used with the Gallup data, the income measure is expressed in deviations from the country's average and outlier observations are excluded from the analysis.

\subsection{Summary Statistics}

The top panel in Table 1 reports summary statistics from the Gallup World Poll for the key variables in our estimations. In the baseline estimations we used data from 103 countries and 54,624 individual observations. The average individual reported a happiness level of 5.5 in the $0-10$ scale with a standard deviation of 2.2. About $22 \%$ of individuals in the GWP reported dissatisfaction with their personal health. The database

\footnotetext{
${ }^{3}$ The number of observations used in our study is substantially limited by the lack of country-specific values for the income variable.
} 
is composed of adult individuals with an average age of 42.2 years and a slightly larger presence of women (55\%) than men (45\%). About $70 \%$ of individuals in our sample are married, fewer than half live in an urban setting (44\%), and 60\% are employed.

The middle panel presents similar summary statistics computed among individuals in the ESS. In the baseline estimations we used data from 27 countries and 32,951 individuals. The average reported happiness was 7.4 in the $0-10$ scale with a standard deviation of 1.8. About $23 \%$ of individuals in the ESS reported dissatisfaction with personal health. The average age is 42.1 years, with a smaller presence of women (48\%) than in the Gallup data. About $66 \%$ of individuals in the sample are married, $68 \%$ live in an urban setting, and $92 \%$ are employed.

The bottom panel presents the corresponding statistics in the WVS. This dataset has information on 38,500 individuals in 41 countries. The average reported happiness was 6.8 in the $0-10$ scale with a standard deviation of 2.4. A larger proportion than in the GWP and ESS report dissatisfaction with personal health (33\%). The average age of 41.2 years is similar, as is the proportion of women (52\%). However, the proportion of married individuals is somewhat higher (79\%) and the proportion of employed individuals is smaller (68\%).

In these tables the income variable is expressed in deviations from the country's average, and because we trimmed outlier observations, the reported means in each dataset may differ from $100 \%$.

[Table 1 about here]

\section{Methodology}

\subsection{Utility function}

In this paper we follow a common assumption in theoretical and applied work and assume a constant relative risk aversion utility function with respect to income (a proxy for consumption):

$$
u(y)=\left\{\begin{array}{lll}
\frac{y^{1-\rho}}{1-\rho} & \text { if } & \rho \neq 1 \\
\log (\mathrm{y}) & \text { if } & \rho=1
\end{array}\right.
$$


where $y$ represents income and $\rho$ corresponds to the Arrow-Pratt coefficient of relative risk aversion $r_{R}$ :

$$
r_{R}=-y \frac{u^{\prime \prime}(y)}{u^{\prime}(y)}=\rho
$$

\subsection{Estimation methodology: happiness and utility}

To use the happiness data we need to hypothesize on the nature of the relation between reported happiness, $h_{i}$, and the individual's experienced utility, $u_{i}=u\left(y_{i}\right)$. For simplicity, Layard, Mayraz, and Nickell (2008) assume that the relation $h_{i}=f_{i}\left(u_{i}\right)$ is linear. Instead, we allow for the relationship $f$ between utility and happiness to be nonlinear and assume only that it needs to be strictly monotonic. We postulate that

$$
h_{i}=f_{i}\left(\mu_{i}+X_{i} \beta\right) \text {, }
$$

where $\gamma$ is a scalar parameter, $X_{i}$ are individual characteristics such as age and gender that do not affect utility from income but do affect happiness, and $\beta$ is a vector of parameters. As in Layard, Mayraz, and Nickell (2008), an important assumption in our methodology is that the relation $f$ is common to all individuals. Therefore, we consider the following model,

$$
h_{i}=f\left(u_{i}+X_{i} \beta+v_{i}\right)
$$

where $v_{i}$ represents an error term that is independent of experienced utility $u_{\mathrm{i}}$.

Since reported happiness is an ordered discrete response, we can operationalize the above model by replacing observed happiness in equation (4) with a continuous latent variable $h_{i}^{*}$ and, assuming that $v_{i}$ has a logistic distribution, allowing $f$ to represent any monotonically increasing transformation. Individuals whose latent happiness is below a certain threshold $\mu_{1}$ will report their happiness level to be at the bottom of the ladder $\left(h_{i}=0\right)$ : 


$$
\operatorname{Pr}\left(h_{i}=0\right)=\operatorname{Pr}\left(h_{i}^{*} \leq \mu_{1}\right)=\operatorname{Pr}\left[f\left(\mu_{i}+X_{i} \beta+v_{i}\right) \leq \mu_{1}\right]
$$

Since $f$ is strictly increasing, it has an inverse function and

$$
\operatorname{Pr}\left(h_{i}=0\right)=\operatorname{Pr}\left[v_{i} \leq \tilde{\mu}_{1}-\mu_{i}-X_{i} \beta\right]
$$

where we define $\tilde{\mu}_{j}=f^{-1}\left(\mu_{j}\right)$.

Similarly, those individuals who report they are on the first step of the happiness ladder, $h_{i}=1$, are those whose latent happiness is above the first threshold, $\mu_{1}$, but below a second cut-off point $\mu_{2}$. This implies

$$
\operatorname{Pr}\left(h_{i}=1\right)=\operatorname{Pr}\left[v_{i}>\tilde{\mu}_{1}-\mu_{i}-X_{i} \beta\right]-\operatorname{Pr}\left[v_{i} \leq \tilde{\mu}_{2}-\mu_{i}-X_{i} \beta\right]
$$

In summary, we have:

$$
\begin{aligned}
& \operatorname{Pr}\left(h_{i}=0\right)=\operatorname{Pr}\left[v_{i} \leq \tilde{\mu}_{1}-\mu_{i}-X_{i} \beta\right] \\
& \operatorname{Pr}\left(h_{i}=j\right)=\operatorname{Pr}\left[v_{i}>\tilde{\mu}_{j}-\varkappa_{i}-X_{i} \beta\right]-\operatorname{Pr}\left[v_{i} \leq \tilde{\mu}_{j+1}-\varkappa_{i}-X_{i} \beta\right] \text { for } 1 \leq \mathrm{j} \leq 9, \text { and } \\
& \operatorname{Pr}\left(h_{i}=10\right)=1-\operatorname{Pr}\left[v_{i}>\tilde{\mu}_{10}-\varkappa_{i}-X_{i} \beta\right] .
\end{aligned}
$$

The last problem is how to separately estimate $\gamma$ and $\rho$. We follow an iterative maximum likelihood procedure as in Layard, Mayraz, and Nickell (2008). First, we compute $u_{i}=u\left(y_{i}\right)$ for values of $\rho$ between 0 and 5 in steps of 0.1 . Second, for each of these computations we estimate $\gamma$ and the vector of parameters $\beta$ with an ordered logit model and save the resulting log-likelihood of the estimation. In the vicinity of the maximum likelihood estimator we repeat this procedure in steps of 0.01 .

To ensure that our results are not affected by outliers in the income reports we trim observations corresponding to the bottom 5\% and the top 5\% of the distribution of residuals of a regression of the log of relative income on individual controls, as in Layard, Mayraz, and Nickell (2008). 


\subsection{Health state dependence}

The previous estimation strategy can be easily extended to analyze the effect of health status on the utility function. We denote by $S_{i}$ (for sick) a dummy variable that takes the value of 1 if individuals provide an affirmative answer to the question on personal health problems and rewrite the equation for the utility function over income and health status as:

$\tilde{u}(y, S)=\gamma_{1} u\left(y_{i}\right)+\gamma_{2} u\left(y_{i}\right) \times S_{i}+\eta S_{i}$.

The coefficient $\eta$ reflects shifts in utility from dissatisfaction with personal health which do not modify the marginal utility income, whereas the coefficient $\gamma_{2}$ represents changes in the marginal utility of income from changes in health status. We use the same iterative procedure previously described to estimate the modified model.

\section{Results}

We perform our estimations for five different sets of countries categorized in terms of income using the World Bank's income classifications: high income OECD, high income non-OECD, upper-middle income, lower-middle income, and low income. We also estimate the models with all the pooled observations and for each country individually. Whenever we pool data from several countries we include country dummies in the estimation.

The top panel of Table 2 reports the estimates of the relative risk aversion coefficient with and without health dependence in the Gallup dataset. The reported coefficients are for the 5 income country classifications, the United States, and the overall pooled estimation. The table also reports likelihood ratio tests for the null hypothesis of $\log$ utility $(\rho=1)$; the bold coefficients indicate statistical significance at the $10 \%$ confidence level.

The estimates of the relative risk aversion coefficient in the Gallup data for the various income groups and the overall estimate without controlling for health dependence range from 0.63 to 0.89 and we do not observe a monotonic relation between income groups and the estimated relative risk aversion coefficient. The estimate with all countries, the estimate for high-income OECD countries, and for low 
income countries are statistically different from 1 (which corresponds to log utility), while the coefficients for high-income non-OECD and lower- and upper-middle income countries are not statistically different from 1 at a $10 \%$ confidence level. The estimate for the United States without health dependence is much higher than the group estimates at 1.48 , but it is not statistically different from 1. Adding health status in the utility function tends to reduce the estimates of the relative risk aversion coefficients across all groups and the United States.

The middle panel reports the estimates of relative risk aversion in the ESS. In this dataset, most countries fall in the either the upper-middle income or high-income OECD classifications. The overall estimate without health dependence is 1.44 and significantly different from 1. Similarly, the estimate for high-income OECD countries is 1.41 and significantly different from 1 . The estimate for upper-middle income countries is 1.06 and not significantly different from 1 . Adding health dependence to the utility function reduces the point estimates for the overall estimates and for high-income OECD countries, but they remain significantly different from 1 .

The estimates with the WVS, reported in the bottom panel, present a picture similar to that for the ESS estimates. The overall estimate (1.16) and those for high-income OECD (1.45), as well as for upper-middle income (1.35), are greater than 1 in magnitude and statistically significantly different from 1 . The estimates for high-income non-OECD (0.71) and for low-income countries (1.35) are not significantly different from 1 . The estimates also generally decline when controlling for health dependence.

[Table 2 about here]

The estimates of relative risk aversion using the Gallup data are lower than those of Layard, Mayraz, and Nickell (2008) and lower than the estimates with the ESS and WVS, especially for high-income OECD countries. The estimates using the ESS and WVS are, in contrast, slightly larger than Layard et al.'s reported range for the elasticity of the marginal utility with respect to income (1.19-1.34). A possible explanation for the disparities among our findings is the composition of countries in the different surveys that were used. The lower estimates with Gallup data are below previous estimations of relative risk aversion that use inferences based on behavioral choices (Friend and Blume, 1975, Weber 1975, Szpiro 1986, Mankiw 1985). However, although the reliability of the income data in the GWP may play a role in explaining the differences in the magnitude of the estimates, our estimates are closer to the results of Hansen and 
Singleton (1983), Cox and Oaxaca (1996), and Bartunek and Chowdhury (1997). The results with Gallup data are also in line with Gandelman and Porzecanski (2011) who also use Gallup data and find that the only way to reconcile happiness inequality with income inequality is with a relative risk aversion coefficient lower than 1 . Most studies using experimental data also find low levels of risk aversion. ${ }^{4}$

Tables 3 through 5 report the estimated coefficients of the individual controls and the cutoff levels in the ordered logit model controlling for health dependence in the utility function. The reported estimations correspond to the maximum likelihood estimator of the coefficients of relative risk aversion reported in Tables 1 and 2. The coefficients reported are odds ratios to facilitate their interpretation because most individual controls are categorical variables. Hence, an odds ratio larger than 1 represents a positive effect on the likelihood of reporting higher happiness levels; an odds ratio smaller than 1 represents a negative effect. Most individual regressors have the expected direction of effect across all datasets.

In Table 3, corresponding to the estimates using the GWP, women are about $20 \%$ more likely than men to report higher levels of life satisfaction ("All countries" column). Similarly, happiness responds positively to marriage: Married individuals are $20 \%$ to $40 \%$ more likely to report higher levels of happiness than non-married individuals (147\% more likely in the United States). Age has a negative effect on the likelihood of higher happiness reports, while its square has a positive effect. Residence in an urban setting has a statistically negative effect for the United States, high-income OECD countries, and low-income countries and a positive effect in other cases. Individuals in the United States who live in urban areas, for example, are $30 \%$ less likely to report higher happiness levels than individuals in rural settings. The coefficient on the urban indicator is not statistically significant for either all countries or lowincome countries categories. The effect of employment status is also positive whenever it is statistically significant; employed individuals are $15 \%$ to $20 \%$ more likely to report higher levels of happiness than unemployed individuals. In terms of health dependence, individuals reporting health problems are less likely to report higher levels of happiness, and the effect is statistically significant for most specifications. The odds ratio varies from 0.488 to 0.640 . The interaction of health status with the utility of income, $u(y)$, has a positive effect (odds ratio greater than 1) and is statistically significant in the

\footnotetext{
${ }^{4}$ Holt and Laury (2002) report relative risk aversion between 0.3 and 0.5 and Andersen et al. (2008) report an estimate of relative risk aversion of 0.74 .
} 
specifications for all countries (1.14), high income OECD countries (1.27), low income countries (1.16) and upper-middle income countries (1.15), and suggests that the marginal utility of income increases for sick individuals. In the overall estimate, for example, an odds ratio of 1.14 indicates that the effect of income on reported happiness is about $14.0 \%$ higher for individuals who report dissatisfaction with personal health. ${ }^{5}$ These results are in contrast with those of Finkelstein, Luttmer, and Notowidigdo (2008). Our findings indicate that controlling for health dependence would suggest that the optimal amount of health insurance or the optimal amount of life cycle savings is higher than when not controlling for health dependence.

[Table 3 about here]

Table 4 presents similar coefficient estimates for the ESS. All individual controls are statistically significant for the estimation with all countries and for high-income OECD countries, but some coefficients are not statistically significant in the case of upper-middle income countries. Women and married individuals are more likely to report higher happiness levels in all three specifications (although the female coefficient is not statistically significant in the case of upper-middle income countries). Residence in an urban setting and employment status also have a positive effect on reported happiness. In contrast, the direct effect of age is negative (but age squared has a positive effect). Similarly, the variable indicating health problems (Sick) has a negative effect. Sick individuals are $50 \%$ to $55 \%$ less likely to report higher levels of happiness (in the case of an odds ratio smaller than 1 , the effect is computed subtracting the coefficient from 1). The interaction of the Sick dummy with the utility of income, $u(y)$, also has a positive effect (odds ratio greater than 1) when it is statistically significant, suggesting that individuals dissatisfied with personal health have a effect from income on reported happiness that is about $9 \%$ higher than individuals who are satisfied with their personal health.

[Table 4 about here]

Finally, Table 5 presents the estimations using the WVS. Again, the magnitude and direction of the effects of the various controls are similar to those reported in Tables 7 and 8. Similarly, the results regarding health dependence are robust. In the overall estimate, for example, the Sick dummy has a negative effect and suggests that

\footnotetext{
${ }^{5}$ Buis (2010) shows that interpreting the odds ratio representation of the ordered logit coefficients as the multiplicative effect of the interaction term is a straightforward alternative to the interpretation of interaction effects in terms of marginal effects, which requires the computation of a cross-partial derivative as in Ai and Norton (2003) and Norton, Wang, and Chunron (2004).
} 
individuals dissatisfied with personal health are $41 \%$ to $67 \%$ less likely to report higher levels of happiness than healthier individuals. The interaction of the health status indicator with the utility of income is also positive and suggests that individuals dissatisfied with personal health have a larger effect from income on reported happiness by about $7 \%$ in the "all counties" estimation and much higher for high-income countries.

[Table 5 about here]

\section{Conclusion}

A significant volume of literature on the implications of behavioral choices for attitudes toward risk yields varying estimates of the coefficient of relative risk aversion. The reported estimates range from nearly linear utility on income (a relative risk aversion coefficient of zero) to estimates implying much more concavity than log utility (corresponding to a relative risk aversion coefficient of 1).

In this paper, we use data from three large surveys that include information on selfreports of subjective well-being, dissatisfaction with personal health, and household income to estimate the coefficient of relative risk aversion and the effect of health state dependence on the utility function. Happiness data, although extensively used in recent years to analyze the effects of inflation and unemployment, among other economic issues, have only recently begun to be used to study risk aversion or the links with personal health. Our paper, and those of Layard, Mayraz, and Nickell (2008) and Finkelstein, Luttmer, and Notowidigdo (2008) are among the first studies in this area.

In contrast to Layard, Mayraz, and Nickell (2008), who report estimates of relative risk aversion that exceed a value of 1 , we obtain estimates that are smaller than 1 in some cases. While we do not study the implications of health status, we find that controlling for health dependence tends to reduce the estimates of relative risk aversion, even in the cases for which we obtain coefficients of relative risk aversion greater than 1 .

Controlling for health state dependence in the specification of the utility function indicates that individuals who are dissatisfied with their personal health are more likely to report lower levels of subjective well-being. Our findings also suggest that the marginal utility of income is higher for individuals who are dissatisfied with their health. This result is robust across all three data surveys and is in contrast with that of 
Documento de Investigación - ISSN 1688-6208 - No. 74 - 2012 - Gandelman, N., Hernández-Murillo, R.

Finkelstein, Luttmer, and Notowidigdo (2008), who find the opposite. This result may prove important for future analysis of the implications of risk attitudes and health status on the optimal amount of health insurance benefits. 


\section{References}

Ai, Chunrong and Norton, Edward C. (2003). "Interaction Terms in Logit and Probit Models.” Economics Letters, 80(1), 123-29.

Andersen, Steffen; Harrison, Glenn W.; Lau, Morten I. and Rutström, E. Elisabet (2008). “Eliciting Risk and Time Preferences." Econometrica, 76(3), 583-618.

Arrow, Kenneth (1965). Aspects of the Theory of Risk Bearing. Helsinki: Yrjö Jahnssonin Säätiö.

Bartunek, Kenneth S. and Chowdhury, Mustafa (1997). "Implied Risk Aversion Parameter from Option Prices.” Financial Review, 32(1), 107-24.

Buis, Maarten L. (2010). “Stata Tip 87: Interpretation of Interactions in Nonlinear Models." Stata Journal, 10(2), 305-8.

Campo, Sandra; Guerre, Emmanuel; Perrigne, Isabelle and Vuong, Quang (2011). "Semiparametric Estimation of First-Price Auctions with Risk-Averse Bidders." Review of Economic Studies, 78(1), 112-47.

Chetty, Raj (2006). “A New Method of Estimating Risk Aversion.” American Economic Review, 96(5), 1821-34.

Cohn, Richard A.; Lewellen, Wilbur G.; Lease, Ronald C. and Schlarbaum, Gary G. (1975). "Individual Investor Risk Aversion and Investment Portfolio Composition." Journal of Finance, 30(2), 605-20.

Cox, James C. and Oaxaca, Ronald L. (1996). "Is Bidding Behavior Consistent with Bidding Theory for Private Value Auctions?" Research in Experimental Economics, 6, 131-48.

Di Tella, Rafael and MacCulloch, Robert (2006). "Some Uses of Happiness Data in Economics.” Journal of Economic Perspectives, 20(1), 25-46.

Easterlin, Richard (1974). "Does Economic Growth Improve the Human Lot? Some Empirical Evidence," in P. David and M. Reder, eds., Nations and Households in Economic Growth: Essays in Honour of Moses Abramovitz. New York and London: Academic Press, 98-125. 
Documento de Investigación - ISSN 1688-6208 - No. 74 - 2012 - Gandelman, N., Hernández-Murillo, R.

Finkelstein, Amy; Luttmer, Erzo and Notowidigdo, Matthew (2008). "What Good is Wealth without Health? The Effect of Health on the Marginal Utility of Consumption." NBER Working Paper No. 14089, National Bureau of Economic Research.

Frey, Bruno S. and Stutzer, Alois (2002). "What Can Economists Learn from Happiness Research?" Journal of Economic Literature, 40(2), 402-35.

Friend, Irwin, and Blume, Marshall E. (1975). “The Demand for Risky Assets.” American Economic Review, 65(5), 900-22.

Gandelman, Néstor and Porzecanski, Rafael (2011). "Happiness Inequality: How Much Is Reasonable?" Social Indicators Research (forthcoming). Published Online First September 6, 2011, doi 10.1007/s11205-011-9929-z.

García, Rene; Luger, Richard and Renault, Eric (2003). "Empirical Assessment of an Intertemporal Option Pricing Model with Latent Variables." Journal of Econometrics, 116(1-2), 49-83.

Gordon, Stephen and St-Amour, Pascal (2004). "Asset Returns and State-Dependent Risk Preferences." Journal of Business \& Economic Statistics, 22(3), 241-52.

Hansen, Lars P. and Singleton, Kenneth J. (1983). "Stochastic Consumption, Risk Aversion and the Temporal Behavior of Asset Returns." Journal of Political Economy, 91(2), 249-65.

Holt, Charles A. and Laury, Susan K. (2002). "Risk Aversion and Incentive Effects." American Economic Review, 92(5), 1644-55.

Layard, Richard; Mayraz, Guy and Nickell, Stephen J. (2008). “The Marginal Utility of Income." Journal of Public Economics, 92(8-9), 1846-57.

Mankiw, N. Gregory (1985). “Consumer Durables and the Real Interest Rate." Review of Economics and Statistics, 67(3), 353-62.

Morin, Roger A. and Fernández Suarez, Antonio (1983). "Risk Aversion Revisited.” Journal of Finance, 38(4), 1201-16.

Norton, Edward C.; Wang, Hua and Ai, Chunron (2004). "Computing Interaction Effects and Standard Errors in Logit and Probit Models." Stata Journal, 4(2), 154-67.

Szpiro, George G. (1986). "Measuring Risk Aversion: An Alternative Approach.” Review of Economics and Statistics, 68(1), 156-9. 
Weber, Warren E. (1975). "Interest Rates, Inflation, and Consumer Expenditures.” American Economic Review, 65(5), 843-58. 
Documento de Investigación - ISSN 1688-6208 - No. 74 - 2012 - Gandelman, N., Hernández-Murillo, R.

\begin{tabular}{|c|c|c|c|c|}
\hline \multicolumn{5}{|c|}{ Table 1 Summary statistics } \\
\hline Variable & Mean & Std. Dev. & Observations & Countries \\
\hline \multicolumn{5}{|c|}{ Gallup World Poll } \\
\hline Happiness & 5.5 & 2.2 & 54,624 & 103 \\
\hline Sick & $22.2 \%$ & $41.6 \%$ & 54,624 & 103 \\
\hline Income & $90.5 \%$ & $55.2 \%$ & 54,624 & 103 \\
\hline Age & 42.2 & 11.3 & 54,624 & 103 \\
\hline Female & $55.0 \%$ & $49.8 \%$ & 54,624 & 103 \\
\hline Married & $70.1 \%$ & $45.8 \%$ & 54,624 & 103 \\
\hline Urban & $43.5 \%$ & $49.6 \%$ & 54,624 & 103 \\
\hline Employed & $60.1 \%$ & $49.0 \%$ & 54,624 & 103 \\
\hline \multicolumn{5}{|c|}{ European Social Survey } \\
\hline Happiness & 7.4 & 1.8 & 32,951 & 27 \\
\hline Sick & $22.6 \%$ & $41.8 \%$ & 32,951 & 27 \\
\hline Income & $95.1 \%$ & $46.1 \%$ & 32,951 & 27 \\
\hline Age & 42.1 & 7.2 & 32,951 & 27 \\
\hline Female & $48.0 \%$ & $50.0 \%$ & 32,951 & 27 \\
\hline Married & $65.6 \%$ & $47.4 \%$ & 32,951 & 27 \\
\hline Urban & $68.1 \%$ & $46.6 \%$ & 32,951 & 27 \\
\hline Employed & $92.4 \%$ & $26.5 \%$ & 32,951 & 27 \\
\hline \multicolumn{5}{|c|}{ World Values Survey } \\
\hline Happiness & 6.8 & 2.4 & 38,500 & 41 \\
\hline Sick & $32.6 \%$ & $46.9 \%$ & 38,500 & 41 \\
\hline Income & $86.9 \%$ & $58.4 \%$ & 38,500 & 41 \\
\hline Age & 41.2 & 7.3 & 38,500 & 41 \\
\hline Female & $52.0 \%$ & $50.0 \%$ & 38,500 & 41 \\
\hline Married & $79.4 \%$ & $40.5 \%$ & 38,500 & 41 \\
\hline Urban & -- & -- & -- & -- \\
\hline Employed & $67.6 \%$ & $46.8 \%$ & 38,500 & 41 \\
\hline
\end{tabular}




\begin{tabular}{|c|c|c|c|c|c|c|}
\hline & \multirow{2}{*}{\multicolumn{3}{|c|}{$\begin{array}{c}\text { Without health dependence } \\
\text { Likelihood ratio }\end{array}$}} & \multirow{2}{*}{\multicolumn{3}{|c|}{$\begin{array}{c}\text { With health dependence } \\
\text { Likelihood ratio }\end{array}$}} \\
\hline & & & & & & \\
\hline & Rho & Chi-squared & p-value & Rho & Chi-squared & p-value \\
\hline \multicolumn{7}{|l|}{ Gallup World Poll } \\
\hline All countries & 0.79 & 19.72 & 0.000 & 0.73 & 28.99 & 0.000 \\
\hline High-income OECD & 0.63 & 16.38 & 0.000 & 0.52 & 24.44 & 0.000 \\
\hline High-income non-OECD & 0.73 & 1.72 & 0.189 & 0.64 & 2.59 & 0.107 \\
\hline Upper-middle income & 0.89 & 2.01 & 0.157 & 0.83 & 4.09 & 0.043 \\
\hline Lower-middle income & 0.83 & 2.31 & 0.128 & 0.81 & 2.43 & 0.119 \\
\hline Low-income & 0.66 & 8.71 & 0.003 & 0.58 & 12.07 & 0.001 \\
\hline United States & 1.48 & 2.13 & 0.145 & 1.39 & 0.54 & 0.464 \\
\hline \multicolumn{7}{|l|}{ European Social Survey $^{\dagger}$} \\
\hline All countries & 1.44 & 18.41 & 0.000 & 1.43 & 13.55 & 0.000 \\
\hline High-income OECD & 1.41 & 14.23 & 0.000 & 1.40 & 10.05 & 0.002 \\
\hline Upper-middle income & 1.06 & 0.05 & 0.826 & 1.15 & 0.21 & 0.644 \\
\hline \multicolumn{7}{|l|}{ World Values Survey } \\
\hline All countries & 1.16 & 3.18 & 0.0747 & 1.08 & 0.59 & 0.4406 \\
\hline High-income OECD & 1.45 & 7.41 & 0.0065 & 1.20 & 1.15 & 0.2840 \\
\hline High-income non-OECD & 0.71 & 0.40 & 0.5254 & 0.92 & 0.03 & 0.8648 \\
\hline Upper-middle income & 1.35 & 6.76 & 0.0093 & 1.38 & 5.55 & 0.0185 \\
\hline Low-income & 1.35 & 1.70 & 0.1925 & 1.33 & 1.05 & 0.3065 \\
\hline United States & 0.92 & 0.10 & 0.7570 & 0.80 & 0.37 & 0.5455 \\
\hline
\end{tabular}

Bold chi-squared test statistics indicate statistical significant at the $10 \%$ level.

The null hypothesis is log utility (relative risk aversion (rho) equal to 1).

$\dagger$ The "Low-income", "Lower-middle income", and "High-income non-OECD" country classifications contain one or zero countries and are omitted. Countries in these classifications are included in the "All countries" results.

\$ The "Low-income" country classification contains just two countries and is omitted. However, countries in this classification are included in the "All countries" results. 
Documento de Investigación - ISSN 1688-6208 - No. 74 - 2012 - Gandelman, N., Hernández-Murillo, R.

\begin{tabular}{|c|c|c|c|c|c|c|c|}
\hline & $\begin{array}{c}\text { All } \\
\text { countries }\end{array}$ & $\begin{array}{l}\text { United } \\
\text { States }\end{array}$ & $\begin{array}{l}\text { High- } \\
\text { income } \\
\text { OECD }\end{array}$ & $\begin{array}{c}\text { High- } \\
\text { income } \\
\text { non-OECD }\end{array}$ & $\begin{array}{l}\text { Low- } \\
\text { income }\end{array}$ & $\begin{array}{l}\text { Lower- } \\
\text { middle } \\
\text { income }\end{array}$ & $\begin{array}{l}\text { Upper- } \\
\text { middle } \\
\text { income }\end{array}$ \\
\hline Sick & $0.573 * * *$ & $0.488^{* * *}$ & $0.469^{* * *}$ & $0.474 * * *$ & $0.640^{* * *}$ & $0.603^{* * *}$ & $0.591 * * *$ \\
\hline$u(y)$ & $1.980 * * *$ & $1.625 * * *$ & $2.438 * * *$ & $2.227 * * *$ & $1.740 * * *$ & $1.762 * * *$ & $1.889 * * *$ \\
\hline Sick* $^{*} u(y)$ & $1.140 * * *$ & 1.122 & $1.270 * * *$ & 1.086 & $1.159 * *$ & 1.080 & $1.146^{* *}$ \\
\hline Female & $1.198 * * *$ & 1.200 & $1.385^{* * *}$ & $1.242 * * *$ & 1.001 & $1.086^{* *}$ & $1.245^{* * *}$ \\
\hline Age & $0.931 * * *$ & $0.888^{* *}$ & $0.876^{* * *}$ & 0.985 & $0.960 * * *$ & $0.947 * * *$ & $0.923 * * *$ \\
\hline $\mathrm{Age}^{2}$ & $1.001 * * *$ & $1.002 * * *$ & $1.001 * * *$ & 1.000 & $1.000^{* * *}$ & $1.001 * * *$ & $1.001 * * *$ \\
\hline Married & $1.199 * * *$ & $2.471 * * *$ & $1.398 * * *$ & 1.104 & 0.990 & $1.151 * * *$ & $1.167 * * *$ \\
\hline Urban & 1.026 & $0.699 * *$ & $0.894 * * *$ & $1.252 * * *$ & 0.994 & $1.132 * * *$ & $1.119^{* * *}$ \\
\hline Employed & $1.154 * * *$ & 0.936 & $1.190 * * *$ & 0.927 & 0.986 & $1.138 * * *$ & $1.270 * * *$ \\
\hline cut 1 & $-8.1213 * * *$ & $-7.5135 * * *$ & $-8.5298 * * *$ & $-5.9705^{* * *}$ & $-5.3012 * * *$ & $-5.3597 * * *$ & $-5.6700 * * *$ \\
\hline cut2 & $-7.2480 * * *$ & $-7.2198 * * *$ & $-7.9158 * * *$ & $-5.4795 * * *$ & $-4.1179 * * *$ & $-4.5326 * * *$ & $-4.8658 * * *$ \\
\hline cut3 & $-6.3461 * * *$ & $-6.0032 * * *$ & $-7.3028 * * *$ & $-4.7018 * * *$ & $-2.9545 * * *$ & $-3.6211 * * *$ & $-4.1522 * * *$ \\
\hline cut 4 & $-5.3651 * * *$ & $-5.4811 * * *$ & $-6.5315 * * *$ & $-3.6878 * * *$ & $-1.8440 * * *$ & $-2.6849 * * *$ & $-3.2610 * * *$ \\
\hline cut5 & $-4.5446^{* * *}$ & $-4.8307 * * *$ & $-5.8685^{* * *}$ & $-2.9172 * * *$ & $-0.9071 * * *$ & $-1.8588 * * *$ & $-2.5301 * * *$ \\
\hline cut6 & $-3.1398 * * *$ & $-3.5088^{* * *}$ & $-4.4854 * * *$ & $-1.4417 * *$ & $0.6438 * *$ & -0.4069 & $-1.2685^{* * *}$ \\
\hline cut7 & $-2.3681 * * *$ & $-2.7492 * *$ & $-3.8009 * * *$ & -0.5362 & $1.7516^{* * *}$ & 0.4322 & $-0.5735^{* *}$ \\
\hline cut8 & $-1.3716^{* * *}$ & -1.6106 & $-2.5729 * * *$ & 0.5654 & $2.7296^{* * *}$ & $1.1632 * * *$ & 0.2680 \\
\hline cut9 & 0.0180 & -0.1178 & $-0.9169 * * *$ & $2.3307 * * *$ & $3.7857 * * *$ & $2.1313^{* * *}$ & $1.2921 * * *$ \\
\hline cut10 & $0.8423 * * *$ & 0.8080 & 0.1757 & $3.2855^{* * *}$ & $4.5026 * * *$ & $2.5304 * * *$ & $1.8661 * * *$ \\
\hline Observations & 54,624 & 612 & 14,976 & 2,647 & 12,181 & 10,713 & 14,111 \\
\hline Countries & 103 & 1 & 28 & 5 & 23 & 20 & 27 \\
\hline Log-likelihood & -104974.1 & -1104.5 & -26900.5 & -4898.8 & -22373.2 & -20979.4 & -28760.2 \\
\hline Pseudo-R ${ }^{2}(\%)$ & 11.00 & 5.99 & 8.27 & 5.10 & 4.67 & 4.68 & 6.00 \\
\hline
\end{tabular}

** Significant at 5\%,*** Significant at $1 \%$

The coefficients are expressed in odds ratios. 
Table 4. Regression with health dependence: European Social Survey.

\begin{tabular}{|c|c|c|c|}
\hline & All countries & High-income OECD & $\begin{array}{l}\text { Upper-middle } \\
\text { income }\end{array}$ \\
\hline Sick & $0.448 * * *$ & $0.446 * * *$ & $0.506 * * *$ \\
\hline$u(y)$ & $1.456 * * *$ & $1.454 * * *$ & $1.762 * * *$ \\
\hline $\operatorname{Sick}^{*} u(y)$ & $1.087 * * *$ & $1.091 * *$ & 0.999 \\
\hline Female & $1.209^{* * *}$ & $1.216^{* * *}$ & 1.153 \\
\hline Age & $0.898 * * *$ & $0.891 * * *$ & 0.939 \\
\hline $\mathrm{Age}^{2}$ & $1.001 * * *$ & $1.001 * * *$ & 1.001 \\
\hline Married & $1.765 * * *$ & $1.782 * * *$ & $1.592 * * *$ \\
\hline Urban & $1.169^{* * *}$ & $1.164 * * *$ & $1.315^{* *}$ \\
\hline Employed & $1.529 * * *$ & $1.550 * * *$ & $1.357 *$ \\
\hline cut1 & $-7.5772 * * *$ & $-7.7942 * * *$ & $-5.4943 * * *$ \\
\hline cut2 & $-6.9384 * * *$ & $-7.1926 * * *$ & $-4.6962 * * *$ \\
\hline cut3 & $-6.1068 * * *$ & $-6.3235 * * *$ & $-4.0184 * *$ \\
\hline cut4 & $-5.3296 * * *$ & $-5.5217 * * *$ & $-3.3369^{*}$ \\
\hline cut5 & $-4.7448 * * *$ & $-4.9195 * * *$ & $-2.8948^{*}$ \\
\hline cut6 & $-3.6448 * * *$ & $-3.8201 * * *$ & -1.7044 \\
\hline cut7 & $-3.0331 * * *$ & $-3.2044 * * *$ & -1.1467 \\
\hline cut8 & $-1.9841 * * *$ & $-2.1441 * * *$ & -0.3786 \\
\hline cut9 & -0.4847 & $-0.6308^{*}$ & 0.5831 \\
\hline cut10 & $0.9399 * * *$ & $0.8094 * *$ & 1.2334 \\
\hline Observations & 32,951 & 31,344 & 1,324 \\
\hline Countries & 27 & 23 & 3 \\
\hline Log-likelihood & -58352.408 & -54995.451 & -2799.1765 \\
\hline Pseudo-R ${ }^{2}(\%)$ & 5.98 & 5.42 & 3.47 \\
\hline
\end{tabular}

* Significant at $10 \%, * *$ Significant at $5 \%, * * *$ Significant at $1 \%$

The coefficients are expressed in odds ratios.

Note: The "Low-income", "Lower-middle income", and "High-income non-OECD" country classifications contain one or zero countries and are omitted. However countries in these classifications are included in the "All countries" results. 
Documento de Investigación - ISSN 1688-6208 - No. 74 - 2012 - Gandelman, N., Hernández-Murillo, R.

\begin{tabular}{|c|c|c|c|c|c|c|}
\hline & $\begin{array}{c}\text { All } \\
\text { countries }\end{array}$ & $\begin{array}{l}\text { United } \\
\text { States }\end{array}$ & $\begin{array}{l}\text { High- } \\
\text { income } \\
\text { OECD }\end{array}$ & $\begin{array}{l}\text { High- } \\
\text { income non- } \\
\text { OECD }\end{array}$ & $\begin{array}{l}\text { Lower- } \\
\text { middle } \\
\text { income }\end{array}$ & $\begin{array}{l}\text { Upper- } \\
\text { middle } \\
\text { income }\end{array}$ \\
\hline Sick & $0.483 * * *$ & $0.254 * * *$ & $0.330 * * *$ & $0.593 * * *$ & $0.586 * * *$ & $0.516^{* * *}$ \\
\hline$u(y)$ & $1.315 * * *$ & $1.870 * * *$ & $1.526 * * *$ & $1.905 * * *$ & $1.180 * * *$ & $1.225 * * *$ \\
\hline $\operatorname{Sick}^{*} u(y)$ & $1.066 * *$ & 0.965 & $1.261 * * *$ & $1.777 * *$ & 1.005 & 1.032 \\
\hline Female & $1.217 * * *$ & $1.354 * * *$ & $1.233 * * *$ & $1.191 *$ & 1.056 & $1.247 * * *$ \\
\hline Age & $0.923 * * *$ & $0.811^{* *}$ & $0.918 * * *$ & 0.950 & 1.032 & $0.889 * * *$ \\
\hline $\mathrm{Age}^{2}$ & $1.001 * * *$ & $1.002 * *$ & $1.001 * * *$ & 1.001 & 1.000 & $1.001 * * *$ \\
\hline Married & $1.514 * * *$ & $1.393 * * *$ & $1.785^{* * * *}$ & $1.322 * *$ & $1.278 * * *$ & $1.487 * * *$ \\
\hline Employed & $1.079 * * *$ & 0.918 & 0.991 & $1.248^{*}$ & 1.101 & $1.071^{* *}$ \\
\hline cut1 & $-4.3396^{* * *}$ & $-9.2767 * * *$ & $-6.9966 * * *$ & $-5.7651 * * *$ & $-2.2437 * * *$ & $-4.7028 * * *$ \\
\hline cut2 & $-3.6066 * * *$ & $-8.6156^{* * *}$ & $-6.1845 * * *$ & $-5.1285 * * *$ & -0.5770 & $-4.2559 * * *$ \\
\hline cut3 & $-3.0178 * * *$ & $-7.7033 * * *$ & $-5.2706 * * *$ & $-4.3831 * * *$ & -0.0561 & $-3.6544 * * *$ \\
\hline cut4 & $-2.5475 * * *$ & $-7.0054 * * *$ & $-4.6132 * * *$ & $-3.7175 * *$ & 0.1903 & $-3.1443 * * *$ \\
\hline cut5 & $-1.6268 * * *$ & $-6.1372 * * *$ & $-3.6419 * * *$ & $-2.7627 *$ & 1.1296 & $-2.2214 * * *$ \\
\hline cut6 & $-1.0884 * * *$ & $-5.5207 * * *$ & $-2.8966 * * *$ & -2.0190 & $1.5153^{*}$ & $-1.7260 * * *$ \\
\hline cut7 & -0.3783 & $-4.3953 * *$ & $-1.8809 * * *$ & -1.1508 & $1.9747 * *$ & $-1.1116^{* *}$ \\
\hline cut8 & $0.5945^{*}$ & -3.0546 & -0.4362 & -0.2081 & $2.3618^{* * *}$ & -0.2429 \\
\hline cut9 & $1.4384 * * *$ & -1.4929 & 0.8119 & 0.6855 & $3.5190 * * *$ & 0.3743 \\
\hline Observations & 38,500 & 1,087 & 10,222 & 1,823 & 5,343 & 20,522 \\
\hline Countries & 41 & 1 & 14 & 3 & 6 & 16 \\
\hline Log-likelihood & -78184.9 & -1975.5 & -18570.6 & -3659.6 & -11406.1 & -41747.1 \\
\hline Pseudo-R ${ }^{2}(\%)$ & 5.88 & 4.10 & 5.82 & 3.13 & 2.88 & 5.82 \\
\hline
\end{tabular}

* Significant at $10 \%, * *$ Significant at $5 \%, * * *$ Significant at $1 \%$.

The coefficients are expressed in odds ratios

Note: The "Low-income" country classification contains just two countries and is omitted. However, countries in this classification are included in the "All countries" results. 